correspondent, Dr. Walters, persists "in pointing out" that I have " missed the point of" or "failed to grasp" an argument which is based upon the merest elementary mathematical principles. My contention is that the argument is inapplicable to the rough British statistics. I am, Sirs, yours faithfully,

March 6th, 1894. THOS. GLOVER LyoN.

\section{"SALINE ENEMATA IN THE TREATMENT OF HAMORRHAGE."}

\section{To the Editors of THE LANCET.}

SIRS, - In an annotation in THE LANCET of Feb. 24th you give an extract from the Allgemeine Wiener Medicinische Zeitung wherein Dr. Warman "draws attention to a new method which he has employed for the administration of salt solution after severe hæmorrhage." Now, what I wish to point out most emphatically is that Dr. Warman's method is not a new one, as I first had the honour of drawing the attention of the profession to this method in THE LANCET of Nov. 3rd, 1888, under the heading of "An Additional Treatment of Post-partum Hæmorrhage," which article I am happy to say induced a large number of practitioners to try it in the above cases as well as in those cases of surgical operation involving a severe loss of blood. Again, in THE LANCET of June 18th, 1892, I more particularly emphasised the points Dr. Warman now puts forward as to its value in the majority of cases over intra-venous injection-viz., that no special apparatus is required, an ordinary enema-syringe or a piece of rubber tubing and a funnel being all that are needed. Moreover, in most cases of post-partum hæmorrhage I take it that the medical attendant would be single-handed, in which case most of his attention would be devoted to the requisite kneading of the uterus or compression of the aorta, which in my experience is scarcely ever to be entrusted to a socalled nurse-usually a neighbour called in to look after the house-while the delicate operation of inserting a cannula into a vein is performed. Again, when this is done the most serious difficulty of all arises-viz, that after boiling the water to free it from germs there is not a single utensil in the house fit to receive it, and, if one starts to sterilise jugs \&c., by the time that has been accomplished the patient would be dead. Dr. Warman points out also the serious risk in intra-venous injection of over-diluting the blood and thus destroying the red corpuscles-a risk, as he truly points out, which is entirely absent from the rectal method. Dr. Spencer, in answer to my letter of June 18th, 1892, says " that there is good reason to believe that in the collapse attending severe hæmorrhage rapid absorption does not take place from the intestinal tract." That this holds good for the stomach I will allow; but in my own cases (happily few) and in the cases I have seen treated by rectal injections at University College Hospital absorption has been most rapid, as evidenced by the improved fulness of the pulse and general condition of the patient; so against Dr. Spencer's dictum I will put forward the following. Dr. Warman states in the above paper that he thinks the fluid is entirely absorbed in less than five minutes ; he says that "the results surpassed all expectations."

A few other cases which have been published, and which I am enabled to refer to, are as follows: Dr. Nicholson ${ }^{1}$ said he was called to a case of abortion and "found the patient in a deplorable condition from the acute anæmia. The pulse was 140 to 150, small, running, and occasionally irregular." She complained of want of air, was unconscious at times, and had constant retching. The patient later became worse, even after raising the foot of the bed and bandaging the legs. $\mathrm{He}$ then employed an enema of a pint of water with a drachm of salt added. He next states that "the effect was extremely beneficial, for within twenty minutes the pulse fell to 120 , the colour improved, and the sickness and faintness almost entirely disappeared." In conclusion, he states: "I feel confident that the saline enema saved the patient's life."

Dr. Reynolds ${ }^{2}$ states that he used the injections in two cases of profuse post-partum hæmorrhage. "It was followed in each case by prompt improvement of the pulse, first in quality and then in frequency." Dr. Fortescue ${ }^{3}$ quotes a case of a man suffering from hæmatemesis, in which an enema of a quart of water was used in order to get the

1 THE LANCET, July 15th, 1893.

2 Brit. Med. Jour., Feb. 11th, 1893.

3 Ibid, Dec, 31st, 1892 bowels to act; none of it returned, "but the patient expressed himself as feeling stronger after the injection." I quote this case as showing that the fear I expressed in $\mathrm{my}$ first letter of having large injections rejected by the bowel is groundless, and, indeed, ever since the first occasion, I have used injections of about a pint at a time.

My object in giving the above cases is to remove the objection so commonly urged against the more general use of saline enemata-viz., that the bowel does not rapidly absorb them. This has been taught for years, but experientia docet, and, unless a number of observers are grossly mistaken, the sooner the old idea is eradicated the better, in order that a metbod capable of universal use and useful in preserving life under critical circumstances may be adopted, to the exclusion of such risky procedures as intra-venous and intraabdominal injections. - I am, Sirs, yours faithfully,

RAINSFORD F. GILL, M.D.Lond.

King Henry's-road, S. Hampstead, N.W., Feb. 26th, 1894

\section{"DECREASE OF THE PRISON POPULATION:" \\ To the Editors of THE LANCET.}

SIRs,-In your annotation on the above subject, which appeared in the last issue of THE LANCET you are perfectly entitled with the information before you to repeat the Registrar-General's charge that I have made an incomprehensible blunder as to the total number of committals to prison. As you have repeated this charge I feel sure you will have the courtesy to allow me the privilege of a reply. When that reply is made you will be able to form your own opinion as to who is the incomprehensible blunderer; in fact, it is only the mysterious exigencies of daily journalism which have prevented the public from forming this opinion before now.

Let me come to close quarters with the Registrar-General's statistics. This official says the committals to prison in 1881 amounted to 109,912 , and in 1891 to 71,635 . I have said, on the other hand, that the total committals to prison in 1881 amounted to 188,586 , and in 1891 to 162,191 . Here is an enormous disparity on an elementary point in criminal statistics. Either I have blundered or the Registrar-General has blundered. In order to see who is in error let us consult the supreme and ultimate authority on these matters-I mean the "Judicial Statistics" of England and Wales. On p. 33 of the "Judicial Statistics" for 1881 and on p. 35 of these Statistics for 1891 we read: "The commitments to each of these prisons during the year ended March 31st, 1882 (and during the year ended March 31st, 1892) were as follow :

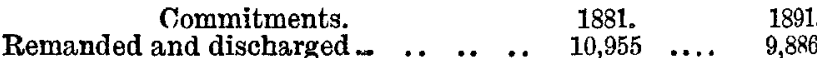

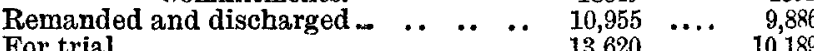

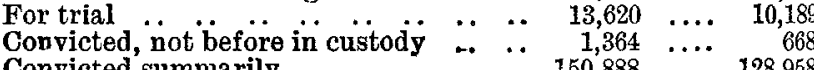

$$
\begin{aligned}
& \begin{array}{llllllllll}
\text { Convicted summarily } & . . & . . & \ldots & . . & . . & 150,888 & \ldots & 128,958
\end{array}
\end{aligned}
$$

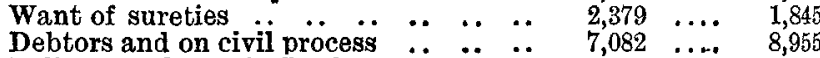

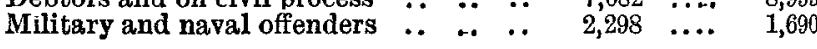

$$
\begin{aligned}
& \text { Totals. . } \\
& \overline{188,586} \ldots \overline{162,191}
\end{aligned}
$$

Compare the figures with my figures, and you will see that they are absolutely the same. Compare them with the Registrar-General's figures and you will see who has perpetrated the "incomprehensible blunder." In order to make assurance doubly sure the courteous officials at the Home Office who draw up our criminal statistics would no doubt willingly verify the tables I have reproduced, although a cursory glance at the "Judicial Statistics" is quite sufficient to convince anyone that the Registrar-General is entirely wrong. Is it too much to ask that this gentleman should withdraw his accusation against me in the same public manner as it was made. I know errors will occur from time to time in public documents, and it is possible that the RegistrarGeneral, who cannot be expected to go over all sorts of figures on his own account, may have been misled by his subordinates. How the Registrar-General has arrived at his erroneous results it is rather difficult to say. In the first place, he has not consulted those parts of the Blue Book which contain the correct figures in a tabulated form. In the second place he has omitted to take account of the fact that a very large number of persons are annually imprisoned in default of payment of fines. One of the most common forms of sentence is a fine of so much or in default so many days or weeks of imprisonment; but the Registrar-General omits this 